\title{
Evaluation of the double coated recycled concrete aggregates for hot mix asphalt
}

\author{
Abbaas Inaayah Kareem ${ }^{1 \mathbf{a}}$, Hamid $\mathrm{Nikraz}^{2}$, and Hossein Asadi $^{3}$ \\ ${ }^{1}$ Ph.D. candidate in the Department of Civil Engineering, Curtin University, Perth, Australia \\ 2 Professor at the Department of Civil Engineering, Curtin University, Perth, Australia \\ ${ }^{3}$ Principal Pavement Engineer GHD Pty Ltd, Brisbane, Australia
}

\begin{abstract}
:
The use of recycled concrete aggregates (RCAs) in pavement industry can mitigate natural aggregates shortage, promote sustainable practices and reduce construction cost. However, the engineering properties of RCAs usually are inferior to those of natural aggregates. In this investigation, a new state of the art coating technique, namely, double coating technique (DCT), is developed to improve strength and durability of the RCAs. The RCAs were firstly coated with a layer of cement slag paste (CSP) to reinforce its weak particles. Then, a second layer of acrylic bitumen emulsion (ABE) was applied to reduce its water/bitumen absorption and enhance the durability. Marshall tests, indirect tensile test, indirect tensile ratio test and indirect tensile resilient modulus test were performed to evaluate intermediate AC14 mixtures made with $0 \%, 20 \%, 40 \%$ and $60 \%$ of double coated recycled concrete aggregates (DCRCAs). The results indicated that the DCT decreases the water absorption of the DCRCAs by $12.3 \%$ and $26.1 \%$ if compared with uncoated RCAs and RCAs coated with CSP respectively. Also, the DCT effectively upgrades the moisture resistance and produces AC14 mixtures with stiffness more than $4000 \mathrm{MPa}$ required for an intermediate layer according to Australian practices.
\end{abstract}


1 Keywords: recycled concrete aggregates, hot mix asphalt, double coating technique, moisture

2 resistance and stiffness.

\section{Introduction}

The construction boom in the developed countries coupled with the natural disasters generates vast quantities of recycled concrete waste (Li, Xiao, \& Zhou, 2009). Wars are also producing tremendous amounts of solid waste the concrete aggregates is the main part of them. Due to those natural disasters and human activities, the recycled concrete waste has been increased 9 (Rafi, Qadir, Ali, \& Siddiqui, 2014). As a result, the RCA's waste has become the most abundant materials in the world (Pourtahmasb \& Karim, 2014). In Australia, this material comprises about 80 percent of the entire quantities of construction and demolition waste (Tam, 2009). The use of this solid waste in hot mix asphalt industry could be the best way for reducing the construction cost (Bhusal \& Wen, 2013), eliminating pollution (Zulkati, Wong, \& Sun, 2013) (Gul \& Guler, 2014) and mitigating natural aggregates shortage (Chen \& Wong, 2013) (Hou, Ji, Su, Zhang, \& Liu, 2014). However, results from the literature have suggested that the quality of the RCAs should be upgraded before being used in HMA production.

Keeping with that, two types of strengthening techniques were used; chemical strengthen technique (CST) and physical strengthen technique (PST) (Lee, Du, \& Shen, 2012) (Hou et al., 2014). While the PST focus on removing the old cement mortar from the RCA surfaces, in the CST different materials have been used to produce the required effect by soaking, sprinkling or coating the RCA particles (Lee et al., 2012). For instance, Katz (2004) treated the recycled aggregates with silica fume solution and ultrasonic cleaning method. Both treatments led to an increase in the compressive strength at ages of 7 and 28 days. Grabiec, Klama, Zawal, and Krupa (2012) modified the RCA by calcium carbonate biodeposition. By this treatment, they 
obtained a reduction in water absorption of recycled aggregates. Saravanakumar, Abhiram, and Manoj (2016) used presoaking surface treatment in three different acidic solutions: hydrochloric acid ( $\mathrm{HCl})$, nitric acid (HNO3) and sulfuric acid (H2SO4). The samples were soaked for 24 hours at room temperature $\left(27-30{ }^{\circ} \mathrm{C}\right)$. It was concluded that these treatments could significantly improve the compressive strength of RCA. Another surface treatment was carried out by (Wang et al., 2017) using microbial carbonate precipitation (MCP). The researchers concluded that their technique reduces the water absorption and increases the compressive strength of RCAs. However, all the above-mentioned techniques were used to improve strength and reduce absorption of RCA used in cement concrete products, and some treatments are not applicable to be used in asphalt concrete mixtures (Hou et al., 2014).

In the past decade, different treatments have been applied to improve the recycled aggregate properties/HMA fabricated with RCAs performance. In this regards, Wong, Sun, and Lai (2007) heated the fine aggregate $(<3.15 \mathrm{~mm})$ at a temperature ranged from $27^{\circ}$ to $950^{\circ} \mathrm{C}$ to produce lime from calcium carbonate. The results from this study revealed that the stiffness and creep characteristics of asphalt mixtures made with heat-treated aggregate were higher than those made with control aggregates. Lee et al. (2012) coated the coarse RCA with cement slag paste (CSP) to improve its resistance to crushing and enhance the mixtures performance. The results showed that HMA made with coated RCA satisfied Taiwanese specification requirements. A different treatment proposed by Zhu, Wu, Zhong, and Wang (2012) to improve the adhesion between RCA particles and asphalt binder and reduce permeability. The coarse RCA particles were pretreated with a liquid silicone resin. The results showed that this technique could enhance the resistance of asphalt mixture to moisture and low-temperature flexibility and result in better rutting performance at elevated temperatures. The authors concluded that the coated RCA with liquid silicone resin could be utilized as aggregate in asphalt mixtures. a R. Pasandín and Pérez (2013) cured the asphalt mixture in an oven for four 
hours at $170^{\circ} \mathrm{C}$ to improve its moisture resistance. The results obtained complied with Spanish specification in terms of Marshall parameters and water invasion resistance. Furthermore, to improve the moisture invasion resistance, A. R. Pasandín and Pérez (2014) coated the RCA with $5 \%$ asphalt emulsion. It was found that this treatment enhances the behavior of the mixtures made with coated RCAs and improves their stripping resistance. Keeping in with RCA-coated with bitumen emulsion, studies on cold asphalt mixture (CAM) made with RCA after being mixed with bitumen emulsion and water are experienced growing trend recently (Gómez-Meijide \& Pérez, 2014) (Gómez-Meijide, Pérez, Airey, \& Thom, 2015) (Nassar, Mohammed, Thom, \& Parry, 2016) (Gómez-Meijide, Pérez, \& Pasandín, 2016). However, CAM seemingly fails in providing the required strength and stiffness to withstand loads subjected to urban roads. Therefore, it is more suitable for construction of rural roads to carry low/medium traffic conditions (Gómez-Meijide \& Pérez, 2014). A different technique was developed by Hou et al. (2014). The RCA was activated with organic silicon resin. The researchers manufactured asphalt mixtures satisfied with all specification requirements in China at percentages less than $60 \%$ RCAs. However, hitherto, none of these techniques have been applied to pavement industry practices. Therefore, a need to develop a new technique, which can bring the RCAs properties/asphalt mixture properties to an acceptable limit of performance, is still required. The importance of such technique is to ease the flow of the RCAs within the community and mitigate its economic/ecological impacts.

\section{Developing the double coating technique (DCT). Requirements}

The aim of developing the DCT is to improve the RCAs properties/asphalt mixtures properties (particularly those mixtures prepared with low-quality aggregates). The concept is based on combining two main previous treatments. This has been done by taking into consideration the performance of the RCAs/asphalt mixtures when previous treatments had been applied. In this 
regard, coating the RCAs with CSP as proposed by Lee et al. (2012) and then, apply another coating layer (bitumen emulsion layer) as proposed by A. R. Pasandín and Pérez (2014) could be suggested. It is expected that coating the RCAs with two layers can produce asphalt mixtures with better performance. On the one hand, the CSP layer reinforces the weak RCAs particles by sealing the pores/cracks presented on the RCAs' surfaces. On the other hand, if a second coating layer (in this study Acrylic Bitumen Emulsion (ABE) is used to form the second coating layer) is applied, it is expected to mitigate the absorptive nature of RCAs coated with CSP (Lee et al., 2012). Thus, due to filling the existed pores on its surfaces. The DCT is expected to reduce the bitumen/water absorption and improve the affinity between the DCRCAs and bitumen. Figure 1, describes the concept of the DCT developed in the present study. At the first stage of the experimental program, the characterization of the DCRCA was carried out to select the optimum CSP coating thickness and the percentage of ABE used. To evaluate The DCRCAs for pavement industry, AC14 asphalt mixtures with $0 \%, 20 \%, 40 \%$ and $60 \%$ of DCRCAs were produced. To provide the same aggregates surface area when a lighter aggregate (DCRCA) being used in HMA production, the substitutions of granite aggregates by DCRCAs were based on a volumetric basis. Thus, a predetermined weight of specific size of granite aggregate is substituted by the same DCRCA size that has equivalent volume. The same percentage of all coarse granite aggregate sizes has been replaced by their corresponding coarse RCAs fractions. Marshall tests, tensile strength test, water sensitivity test and indirect tensile resilient modulus test were conducted to evaluate the road behavior of the asphalt mixtures. 


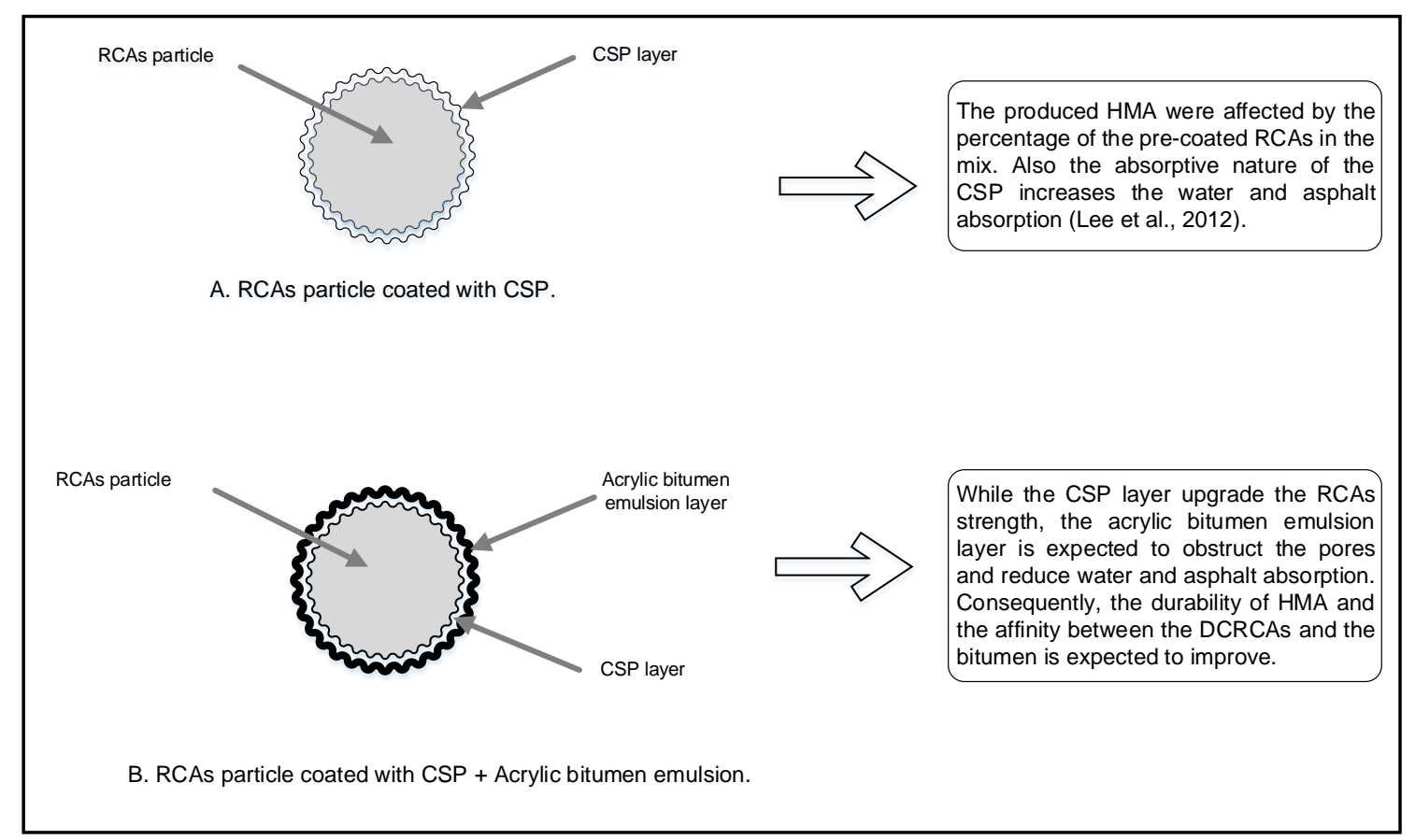

Fig. 1. The concept of the double coating technique (DCT).

\section{Materials and methods}

\subsection{Materials}

\subsubsection{Natural and recycled aggregates}

A crushed granite aggregate was used as a control aggregate in this study. This aggregate was sourced from a local quarry in Western Australia in fractions of 0/5, 5, 7/10 and $14 \mathrm{~mm}$. It was confirmed that the granite aggregates complied with Australian standards to be used as aggregate in pavement infrastructure. In addition, one type of RCAs was sourced from Capital Recycling, the main supplier in the Perth region. The recycled aggregates consisted of $83.4 \%$ of crushed recycled concrete, $7.8 \%$ of high-density brick and tile and about $7 \%$ of recycled asphalt pavement (RAP). The remainder solid waste were metals, glass, ceramics, plastic, plaster and organic matters, all of these accounts for $1.5 \%$. The basic properties of granite and RCAs are shown in Table 1. The results indicated that the coarse and fine RCAs had lower densities than granite aggregates. The coarse and fine RCAs had water absorption equal to 
14.25 and 10.5 times the water absorption of coarse and fine granite aggregates respectively.

111 Also, according to Australian standards, the RCAs did not comply with Los Angeles abrasion coefficient requirement and water absorption limitation. This is owing to the old cement mortar attached to RCA and other impurities such as brick and tile. In this study, it was decided to use the coarse RCAs only (particles $>4.75 \mathrm{~mm}$ ) in HMA production for three main reasons:

- The impurities such as the wood, metal, plastic and gypsum plaster can be eliminated by visual inspection.

- Some of the later mentioned impurities could be presented in fine fraction within fine recycled aggregates and would be difficult to remove (a R. Pasandín \& Pérez, 2013).

- The water absorption of fine recycled aggregates is higher than coarse recycled aggregates, which might affect the durability and increase the amount of bitumen required to achieve the optimum bitumen content (OBC) (Bhusal, Li, \& Wen, 2011).

Table 1

Basic properties of natural aggregates and recycled aggregates.

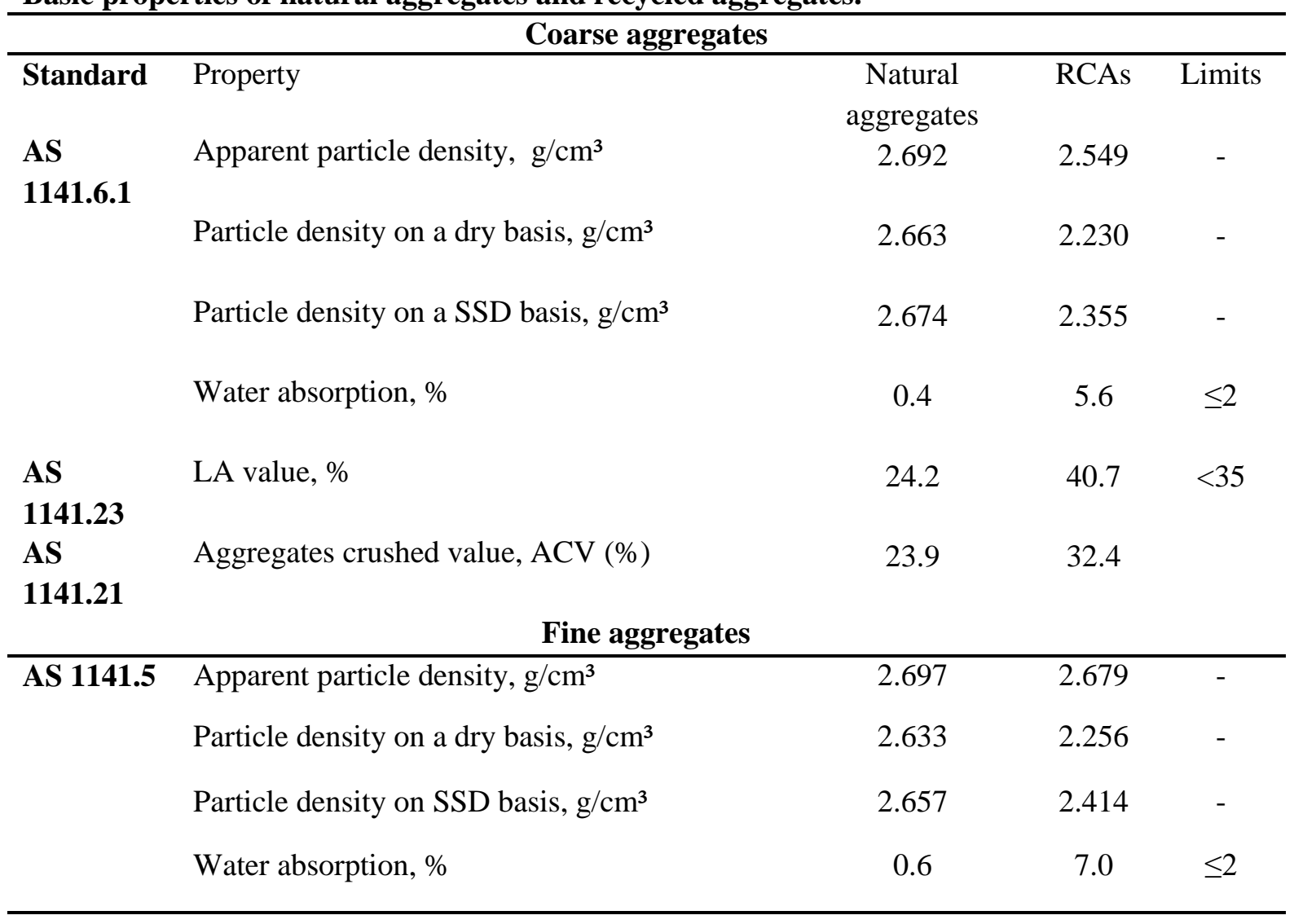




\subsubsection{Filler}

124 One type of filler was used in this study, which is the natural dust producing from crashing process of granite aggregates.1.5\% lime by weight of dry aggregates was added to the mix as recommended by Main Roads Western Australia Standard (MRWA, 2017).

\subsubsection{Bitumen}

Class 320 was used in this study. This bitumen had a penetration value of 50 at the standard test conditions $\left(25^{\circ} \mathrm{C}, 100 \mathrm{~g}\right.$, and $\left.5 \mathrm{~s}\right)$, a flash point higher than $300^{\circ} \mathrm{C}$, and a density of 1.03 $\mathrm{t} / \mathrm{m}^{3}$. It was confirmed that this bitumen complied with all Australian standards requirements.

\subsubsection{Cement, granulated blast furnace slag (GBFS), and SikaHWR}

Type GP cement mixed with $15 \%$ of granulated blast furnace slag (GBFS) are used to form the

CSP for the first coating layer. They have chemical specifications described in Table 2. The fixed percentage, $0.8 \%$, for all CSP mixes. The physical and chemical properties of this superplasticizer are shown in Table 3.

\section{Table 2}

The chemical composition/information on ingredients of type GP cement, and GBFS.

\begin{tabular}{|c|c|c|c|}
\hline Type GP cement & & GBFS & \\
\hline Ingredient & Content & Ingredient & Content \\
\hline Portland Cement & $<97 \%$ & Quartz & $<1 \%$ \\
\hline Blast Furnace Slag & $0-5 \%$ fredient & Chromium trioxide $_{\text {Formula }}$ & $<0.1 \%$ \\
\hline Gypsum & $3-8 \%$ & Ground blast furnace & $>90 \%$ \\
\hline Limestone & $0-5 \%$ & Calcium sulphate & 2 to $5 \%$ \\
\hline Chromium (VI) & $<20 \mathrm{ppm}$ & & \\
\hline GirystadimertSilica, Quartz & Formul $0 r 25 \%$ & rone & CAS No \\
\hline
\end{tabular}




\section{Table 3}

Physical and chemical properties of Sikament@NN.

\begin{tabular}{lc}
\hline Physical state & Liquid \\
Color & Brown \\
Odor & Characteristic \\
Density & 1.19 to $1.23\left(\mathrm{~g} / \mathrm{cm}^{3} @ 25^{\circ} \mathrm{C}\right)$ \\
$\mathrm{pH}$ & 8 to 9 \\
\hline
\end{tabular}

\subsubsection{Sika Tite-BE}

In this study, the Sika Tite-BE, acrylic based bitumen waterproofing membrane (here named as $\mathrm{ABE}$ ) was used to form the second coating layer. This product is supplied by Sika Australia Pty Limited. The physical and chemical properties of this product are shown in Table 4 . The product is suitable for use on a variety of building materials such as concrete, render, masonry and asphalt. Based on supplier recommendations, it should be applied at a minimum of two coats.

\section{Table 4}

Physical and chemical properties of Sika Tite-BE.

\begin{tabular}{lc}
\hline Physical state & Liquid \\
Color & Black \\
Odor & Characteristic \\
Volume of solids & $40 \%$ \\
Density & $\sim 1.2 \mathrm{~g} / \mathrm{cm}^{3}\left(20^{\circ} \mathrm{C}\right)$ \\
Boiling point & $100^{\circ} \mathrm{C}$ \\
\hline
\end{tabular}

\subsection{Methods}

\subsubsection{Marshall mix design}

Four AC14 asphalt mixtures were prepared with $\% 0, \% 20, \% 40$, and $\% 60$ of DCRCAs according to Australian Standards. The optimum bitumen content for mixtures was determined using standard Marshall method (Australian/New Zealand Standards, 2015). The Marshall parameters were determined at $5 \%$ air voids content for each mix. After RCA-coated with CSP was coated with ABE, the DCRCA was kept in a good ventilated area to allow for water to be 
evaporated. Then, it mixed with coarse and fine granite aggregates, and filler and heated

158

159

160 overnight at $175{ }^{\circ} \mathrm{C}$ before mixing with bitumen to manufacture HMA. For asphalt mixtures made with DCRCAs, the proportion by mass of the binder absorbed (b), the proportion by mass of the effective binder (Be), VMA and VFB were determined after taking into account the change in gradation which happens during the mixing and compaction processes. For the nomination of the asphalt mixtures, a specific nomenclature was used; two capital letters $\mathrm{CB}$, where $\mathrm{C}$ refers to $\mathbf{C S P}$ layer and $\mathrm{B}$ refers to $\mathrm{ABE}$ layer. Then, a number refers to the RCA's dosage in the mix followed by a capital $\mathrm{R}$ to refer that these mixes were prepared with recycled aggregates. For instance, CB20R is referring to the HMA prepared with $20 \%$ of DCRCAs, and $\mathrm{OR}$ is referring to the HMA prepared with granite aggregates. Figure (2) shows the selected gradation and the upper and lower limits for AC14 grading curve based on AS 2150 (Standards Australia, 2005). 
200

\subsubsection{Indirect tensile strength (ITS) and moisture sensitivity test}

D 6931 test method (ASTM, 2017) was used to determine the indirect tensile strength (IDT) of AC14 made with $0 \%, 20 \%, 40 \%$ and $60 \%$ of DCRCAs. To check the effect of air voids content on tensile strength, specimens made with $5 \%$ and $8 \%$ air voids were tested at $25^{\circ} \mathrm{C}$. In addition, to check the effect of temperature on the tensile strength, another series was prepared with $5 \%$ air void content and tested at $40^{\circ} \mathrm{C}$. Each series were contained three specimens To evaluate the moisture resistance of mixtures made with granite and DCRCAs, the test method AG: PT/T232 was performed (Austroads, 2007). In TSR test, four series consisting of six specimens each were prepared. One series was made with granite aggregates, and the other three series were fabricated with $20 \%, 40 \%$ and $60 \%$ of DCRCAs. Specimens of $100 \pm 2 \mathrm{~mm}$ in diameter and $65 \pm 1 \mathrm{~mm}$ in height were made with their determined optimum bitumen content. Each group was divided into two sets of specimens: dry (unconditioned) and wet (conditioned). The wet set was subjected to freeze-thaw cycle at a test temperature of between $-18^{\circ} \mathrm{C}$ and $60^{\circ} \mathrm{C}$. The indirect tensile strength of the dry and wet specimens was tested at $25^{\circ} \mathrm{C}$ with a loading rate of $50 \mathrm{~mm} / \mathrm{min}$. The tensile strength can be calculated using Eq. (1):

$T S=\left(\frac{2 P}{\pi * H * D}\right) * 10^{6}$

Where TS is the tensile strength $(\mathrm{kPa}), \mathrm{P}$ is the maximum applied force measured by the testing machine $(\mathrm{kN})$, and $\mathrm{H}$ and $\mathrm{D}$ are the height and diameter of a specimen in $(\mathrm{mm})$.

The ratio between the wet to dry tensile strength is called a tensile strength ratio (TSR), which is expressed as a percentage and can be computed using the following Eq. (2):

$T S R=\frac{T S W}{T S D} * 100$

Where TSR is the tensile strength ratio (\%), TSW is the average tensile strength of the wet specimens $(\mathrm{kPa})$, and TSD is the average tensile strength of the dry specimens $(\mathrm{kPa})$. 


\subsubsection{Indirect tensile stiffness modulus test}

204

205

206

207

208

209

210

211

212

213

214

215

216

217

218

219

220

221

222

The indirect tensile stiffness modulus (ITSM) test was conducted to determine the resilient modulus of the control mix and mixes made with DCRCA using a universal testing machine (Australian/New Zealand Standard, 2013). Since the air voids are indirectly affected the resilient modulus value, the specimens were compacted at their OBC using the gyratory compactor to a desired air voids content $(5 \pm 0.5)$. The ITSM test is a nondestructive test where the compressive haversine load pulse was applied vertically in the vertical diameter of a cylindrical specimen through a curved loading strip. A total horizontal strain of $50 \pm 20$ microstrains should be achieved in the specimen under test. This is to ensure that the specimen sufficiently deformed while its response to the deformation remains elastic. At first, five conditioning pulses of load were applied at a required rise time to the peak load and a required pulse period. Then a further five load pulses were applied and used to determine the resilient modulus of the specimen. The test was conducted in a temperature controlled chamber at $25 \pm 0.5^{\circ} \mathrm{C}$ and $40 \pm 0.5{ }^{\circ} \mathrm{C}$. Table 5 shows the test conditions of the ITSM test. The resilient modulus (E) for each load pulse was determined using Eq. (3):

$E=P * \frac{(v+0.27)}{(H * h c)}$

Where $E$ : resilient modulus $(\mathrm{MPa}), P$ is the peak load $(\mathrm{N}), v$ is the Poisson ratio $(0.4$ was assumed for all asphalt mixes), $H$ is the recovered horizontal deformation of specimen after application of load (mm) and $h c$ is the height of the specimen ( $\mathrm{mm})$.

\section{Table 5}

Test conditions of the ITSM test

\begin{tabular}{lc}
\hline Rise time $t u$ (10\% to $90 \%), \mathrm{ms}$ & $40 \pm 5$ \\
Pulse repetition period (10\% to $10 \%), \mathrm{ms}$ & $3000 \pm 5$ \\
Recovered horizontal strain, $\mu \varepsilon$ & $50 \pm 20$ \\
\hline
\end{tabular}




\section{DCRCAs fabrication}

This part of the study aims to summarize the main steps that have been followed to determine the thickness of CSP coating layer. It also discusses how to determine the percentage of ABE which needs to be mixed with the RCAs coated with CSP to form the second coating layer. A series of CSP mixes were fabricated using four different theoretical coating thicknesses; 0.05 $\mathrm{mm} 0.1 \mathrm{~mm}, 0.2 \mathrm{~mm}$ and $0.4 \mathrm{~mm}$. The steps used by Lee et al. (2012) to compute the weight of cement slag paste for each RCAs size were followed in this investigation. All RCAs coated with CSP allowed to be hydrated in water for seven days. The LA abrasion, water absorption, the apparent particle density (Qa), the particle density on a dry basis (Qd), the particle density on a saturated surface dry basis (Qssd) and the visual inspection were used to determine the optimal thickness of CSP coating layer. The visual inspection was conducted to assess the applicability of specified thickness into the site practices. Regarding the second coating layer, it is recommended by the supplier that if the $\mathrm{ABE}$ is applied on concrete/masonry materials, the first coat can be formed by mixing 1 part of ABE with 3 parts of water. However, on asphalt/bitumen, the prime coating layer needs to be formed by mixing 1 part of ABE with 1 part of water. Therefore, since the RCAs used contains about 7\% RAP; the first coat was formed by mixing 1 part of ABE with 2 parts of water. 5\% (by the weight of dry RCA-coated with CSP) of this mixture ( $1 \mathrm{ABE} / 2$ water) was added to the coated RCAs with CSP and mixed thoroughly for about two minutes. After 3 to 4 hours, a second coat was applied as recommended by the supplier. This coat was formed using 2 parts of $\mathrm{ABE}$ and 1 part of water. $3.5 \%$ (by the weight of dry RCA-coated with CSP) of this mix was applied to the coated recycled aggregates and mixed thoroughly for about two minutes. Increasing the percentage of $\mathrm{ABE}$ in the second coat aims into effectively sealing the pores presented on the RCAs coated with CSP and thus; the absorptive of those particles could be mitigated. This expects to reduce 
the water/bitumen absorption of the DCRCAs and upgrades its affinity with bitumen. Figure 3 shows the uncoated RCAs, RCAs coated with CSP and the DCRCAs.
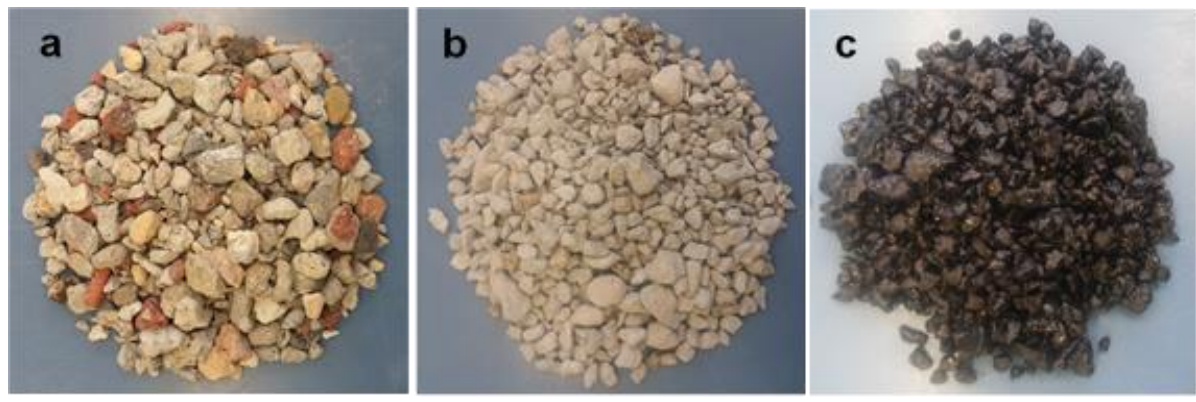

Fig. 3. (a) Uncoated RCAs, (b) RCAs coated with CSP, (c) double-coated RCAs.

\section{Results and discussion}

\subsection{DCRCA properties}

Table 6 shows the properties of RCAs coated with CSP. It was found that as the CSP coating thickness increased the water absorption rate increases while the densities decrease. Therefore, the first coating layer produces a degrading effect in terms of density and water absorption. The results of LA test showed an improvement in the abrasion resistance of the RCAs coated with CSP. It can be seen that when the CSP coating thickness increased, the resistance to abrasion increases until $0.2 \mathrm{~mm}$ CSP. After that, the LA abrasion resistance decreased. In this respect, at a thinner coating thickness, the pores/cracks were filled with the coating paste, and this reinforces the weak RCAs particles. However, the increase in CSP coating thickness produces a decrease in LA resistance and density, an increase in water absorption and causes RCA's particles to get cemented to each other. The visual inspection showed that the RCAs' particles smaller than $13.2 \mathrm{~mm}$, coated with a CSP thickness $\geq 0.2$ mm CSP, tend to cement to each other and it was difficult to be separated. Based on the results 
275

obtained, the optimal CSP coating thickness selected was $0.1 \mathrm{~mm}$. The results indicated that the DCT decreases the water absorption of the DCRCA by $12.3 \%$ and $26.1 \%$ if compared with uncoated RCAs and RCAs coated with $0.1 \mathrm{~mm}$ CSP respectively. The results also revealed that the ABE layer slightly improves the ACV of the DCRCAs as shown in Table 6. This could be due to filling the pores presented in CSP layer.

Table 6

The properties of RA coated with CSP and the DCRCA.

\begin{tabular}{lcccccc}
\hline property & \multicolumn{7}{c}{ RCAs coated with CSP, mm } & DCRCA & Standard \\
& 0.05 & 0.1 & 0.2 & 0.4 & & \\
LA abrasion, \% & 39.3 & 38.8 & 37.8 & 38.5 & - & AS1141.23 \\
Aggregate crashed value (ACV) & - & 30.7 & - & - & 30.3 & AS1141.21 \\
Apparent density (Qa), g/cm ${ }^{3}$ & 2.581 & 2.585 & 2.581 & 2.578 & 2.437 & AS1141.6.1 \\
Density on a dry basis (Qd), g/cm ${ }^{3}$ & 2.203 & 2.199 & 2.193 & 2.152 & 2.172 & \\
SSD density (Qssd), g/cm & 3.349 & 2.348 & 2.343 & 2.317 & 2.280 & \\
Water absorption, \% & 6.62 & 6.77 & 6.84 & 7.67 & 5 & \\
\hline
\end{tabular}

\subsection{Marshall tests}

Figure 4 shows Marshall properties of the mixtures made with control and DCRCA aggregates. The results indicated that DCRCA-mixtures had a lower bulk density if compared with those made with granite aggregates. This is because of the lower density of the DCRCAs compared to those of control aggregates. Figure 4 reports the stability values obtained for the four fabricated mixtures. It can be seen that the stability values for mixtures made with DCRCAs were close or even higher than the stability of control mix. This could be because of the double effect of the new coating technique where the CSP layer improves the strength, and the ABE layer upgrades the affinity with bitumen. In addition, the flow values of the tested mixes where within the specified limits by Australian standards and its value was increased as the DCRCA percentage increases. The OBC where computed at $\% 5$ air voids and it was $4.2 \%, 4.5 \%, 4.8 \%$ and 5\% for HMA made with 0, 20, 40 and 60\% DCRCAs respectively. These OBC values of mixes made with DCRCAs were lower than those made with $20 \%, 40 \%$ and $60 \%$ uncoated 
289 RCAs. But, the DCRCAs still require more bitumen than granite aggregates to achieve the 290 OBC. It can be seen that the OBC increased as the DCRCA dosage increases, however; at the 291 OBC, the effective bitumen content (Be) was almost the same for all asphalt mixes. This is 292 confirmed that increasing the amount of bitumen to satisfy the optimum limit was because 293 increasing the amount of the absorbed bitumen as shown in Figure 4. Although the results of 294 the VMA do not follow a definitive trend, in general, the VMA was decreased as the DCRCAs 295 percentage increases. This may result because the increase in the bitumen absorption by the 296 DCRCA as shown in Figure 4. The values obtained for VFB have followed a definitive trend 297 that is: the VFB decreased as the dosage of DCRCAs increases. These results may be due to 298 increasing the percentage of absorbed bitumen. All mixtures had VFB values higher than $60 \%$. 299 But, the values of VMA do not satisfy the minimum requirements for VMA of 15\% (Standards 300 Australia, 2005). However, according to Standards Australia (2005), it is unusual to specify 301 limits for both VMA and VFB. 

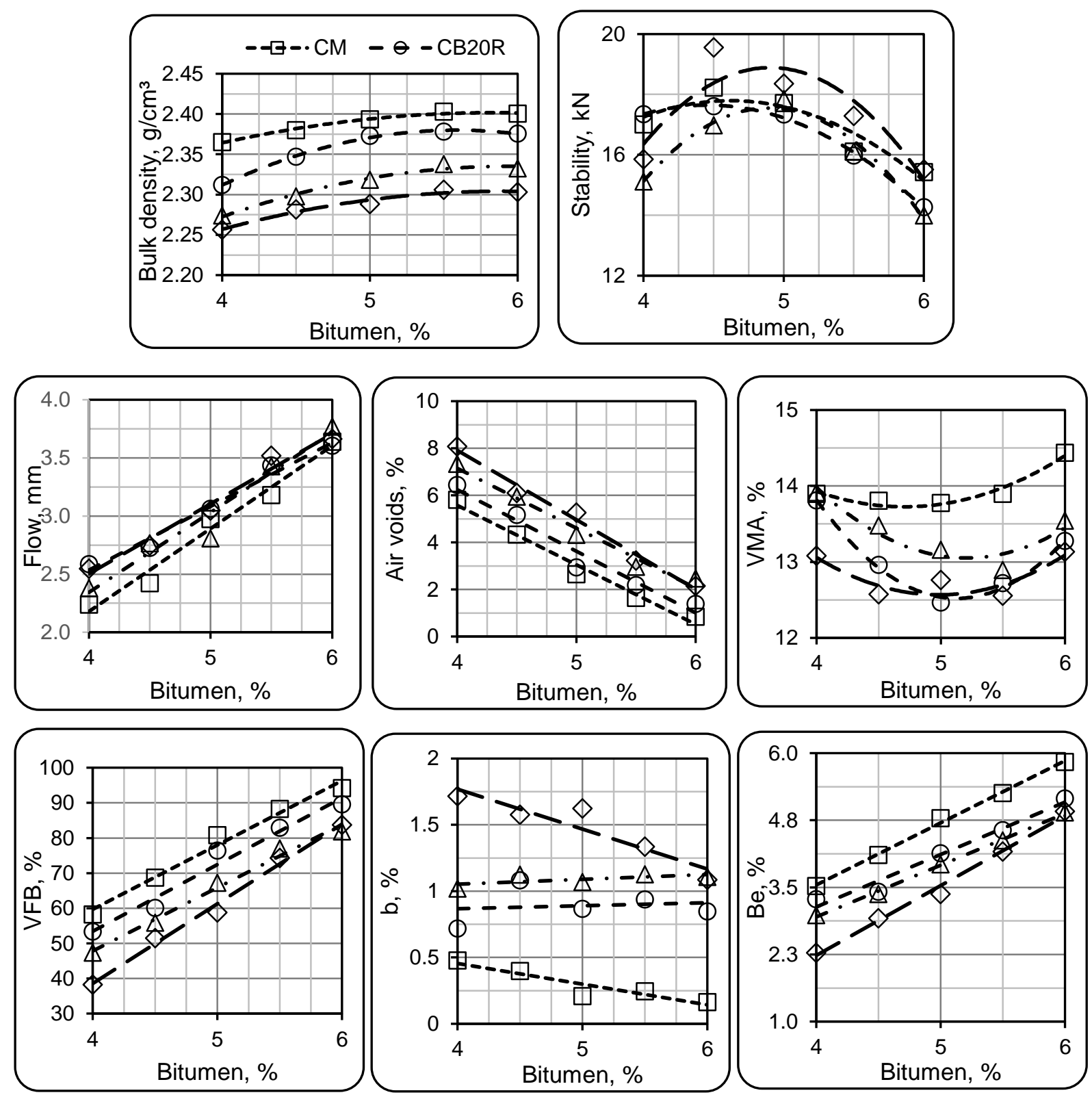

302

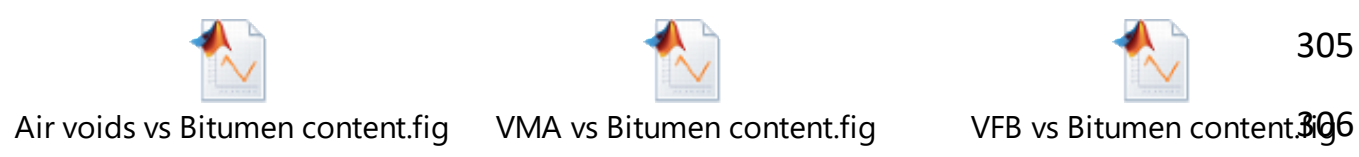

Fig. 4. Marshall parameters for control and HMA made with DCRCAs. 


\subsection{ITS test results}

311

312

313

314

Figure 5 shows the results of the ITS test at two test temperature $\left(25^{\circ} \mathrm{C}\right.$ and $\left.40^{\circ} \mathrm{C}\right)$ and two air voids content of $5 \pm 1 \%$ and $8 \pm 1 \%$. The results indicated that the ITS decreased as the test temperature/air void contents increased. This proves that the HMA is highly affected by both test temperature and void contents. The mixtures prepared with DCRCAs exhibited lower tensile strength (TS) than control mix. Only one exception was noticed, the CB20R tested at $25^{\circ} \mathrm{C}$ and $\mathrm{AV}=8 \% \pm 1$ had $\mathrm{TS}$ higher than $0 \mathrm{R}$ mix. The heterogeneity of the recycled aggregates used might explain this behavior. The results indicated, in general, that the DCRCAs used in HMA degrades the tensile strength of the mix. Therefore, the double coating technique produces a decrease in the friction forces that can be mobilized between the DCRCAs particles after obstructing the pores/cracks presented on the RCAs' surfaces. It can also be seen that the TS of the HMA made with $20 \%, 40 \%$ and $60 \%$ DCRCA were close to each other indicating that the DCT diminishes the difference between the TS of those mixtures.

A two way ANOVA is done to examine the impact of DCRCAs dosage and air voids (5\% and $8 \%$ ) on the TS of different mixes. Another two way ANOVA is performed to test the effect of the DCRCA percentage and test temperature on the TS. The first ANOVA showed that both factors (\%DCRCA and air void content) were significant at 95\% confidence level $(p=0.000)$. In addition, the second ANOVA indicated the significant effects of both investigated factors (\%DCRCA percentage and test temperature) on TS $(\mathrm{p}=0.000)$. Based on ANOVA, the DCRCA dosage has more effect on the TS when the test is performed at different temperatures $(\mathrm{p}=0.000)$, not at different air void contents $(\mathrm{p}=0.001)$. Thus, any change in the DCRCA percentage, and test temperature/air void will produce a change in the TS of DCRCA-asphalt mixes. 
Fig. 5. ITS test results.

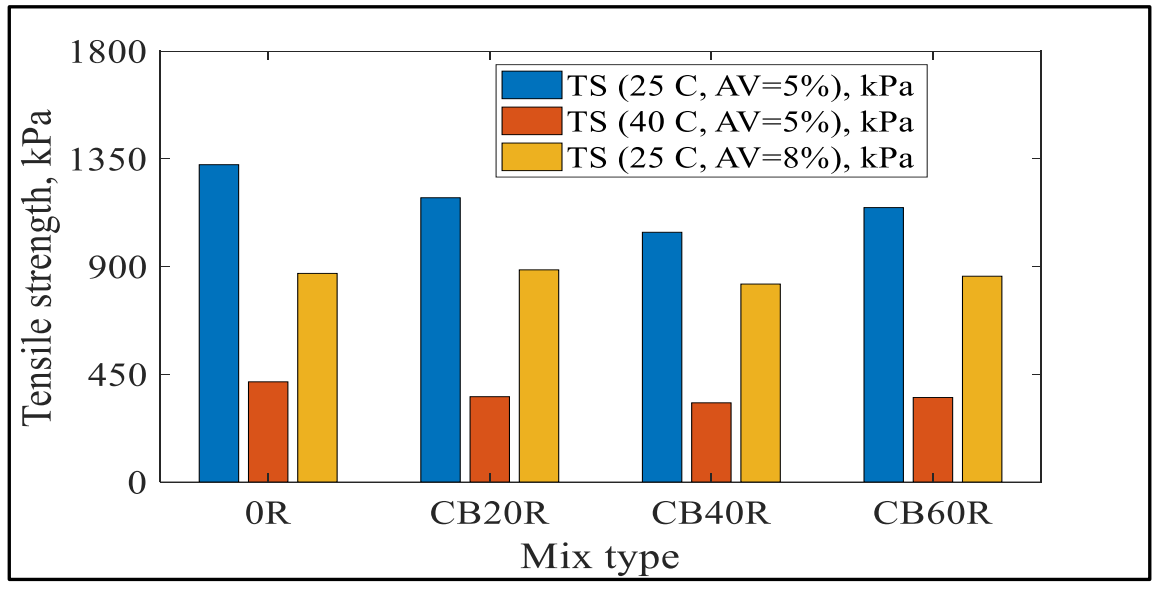

Figure 5, ITS test results.fig

\subsection{TSR test results}

The results of the moisture invasion tests for asphalt specimens made with DCRCAs are shown in Figure 6. According to the results, in general, there was a decrease in the TSR by the addition of the DCRCAs to the mix. Also, the TSR results were not following a definitive trend. This may be because of the higher water absorption of the DCRCAs compared with granite aggregates and the heterogeneity of the RCAs used in the study. Generally, the new state of the art DCT decreases the average tensile strength of dry samples. These results are contradicted by the results obtained by Lee et al. (2012) where the TSD was found to increase with increasing the percentage of RCA-coated with CSP in the mix. Therefore, it could be expected that when the RCA-coated with CSP was coated with ABE, the mobilized friction forces by the DCRCA-asphalt mixtures is decreased. Furthermore, the DCT reduces the TSW when compared with those obtained for control mix. It can be seen that the new state of the art DCT reduces the rate of differences between the dry and wet TS of mixes made with DCRCA as shown in Figure 6. In addition, the DCT enhances the water invasion resistance of DCRCAasphalt mixtures by leaving no space for water to enter between bitumen and the DCRCA surfaces. Therefore, the observed TSW of mixes made with $20 \%, 40 \%$, and $60 \%$ DCRCAs was 
close to TSD obtained for the same mixtures as shown in Figure 6. As a result, the gap between dry and wet TS is reduced, and TSR higher than $98 \%$ is produced.

A one-way analysis of variance (ANOVA) was conducted to investigate the effect of DCRCAs percentage on the TSR of the asphalt mixes. The ANOVA indicates, that the percentage of the DCRCAs is significantly affected the TSR at the 95\% confidence level $(\mathrm{P}=0.000<0.05)$. Therefore, any change in the DCRCA percentage will produce a change in the water invasion resistance of the produced mix. Another two way ANOVA was carried out to study the effect of DCRCAs percentage and the state condition (dry or wet) on the TS. By the ANOVA analysis, the DCRCA\% is not statically significant $(\mathrm{P}=0.402>0.05)$. The two way ANOVA also confirms that the dry and wet state is also not significant from a statistical viewpoint where $\mathrm{P}=0.949>0.05$. The results revealed that the DCT provides a protective action onto RCAs used and reduces the difference between the tensile strength in the dry and wet state, as explained before, regardless the percentage of DCRCA used in the mix.

\subsection{ITSM test results}

Figure 7 shows the ITRM test results at $25^{\circ} \mathrm{C}$ and $40^{\circ} \mathrm{C}$. The results confirmed that the HMA is a visco-elastic material and an increase in testing temperature will result in a reduction in the 
material resilient modulus/stiffness. The results of the ITRM test at $25^{\circ} \mathrm{C}$ revealed that utilization of DCRCAs in HMA production produce a decrease in asphalt mix stiffness. This may be because the DCRCAs still had a lower quality if compared with granite aggregates, as shown in Table 1 and 7. Another reason might be the higher OBC of the mixes fabricated with DCRCA which may produce a decrease in the resilient modulus (Paranavithana \& Mohajerani, 2006). However, when the test temperature was elevated to $40^{\circ} \mathrm{C}$, a different behavior was observed. The resilient modulus values were decreased as the DCRCAs dosage increases from $20 \%$ to $40 \%$ and then to $60 \%$, but these values were higher than those obtained for control mixes up to $40 \%$ granite aggregate substitution. This improvement in asphalt mix stiffness at high temperature needs further investigations. According to the Australian practices, the typical values of resilient modulus for dense-graded asphalt to be used as wearing layer, intermediate/base layer or fatigue layer is; 3000, 4000 and $3000 \mathrm{MPa}$ respectively (Austroads, 2008). Therefore, although; the asphalt mixes made with DCRCA are planned to serve as an intermediate layer, however; the DCRCA-asphalt mixes tested at $25^{\circ} \mathrm{C}$ satisfy Australian the test temperature on the asphalt mixture stiffness. The results of the ANOVA indicates that both investigated factors are statically significant at a 95\% confidence level. However, the test temperature is more significant $(\mathrm{P}=0.000)$ than the percentage of DCRCA $(\mathrm{P}=0.001)$. Depend on this; the test temperature is the most influential factor in determining the stiffness of the asphalt mixes made with DCRCA. 
Fig. 7. ITSM test results.

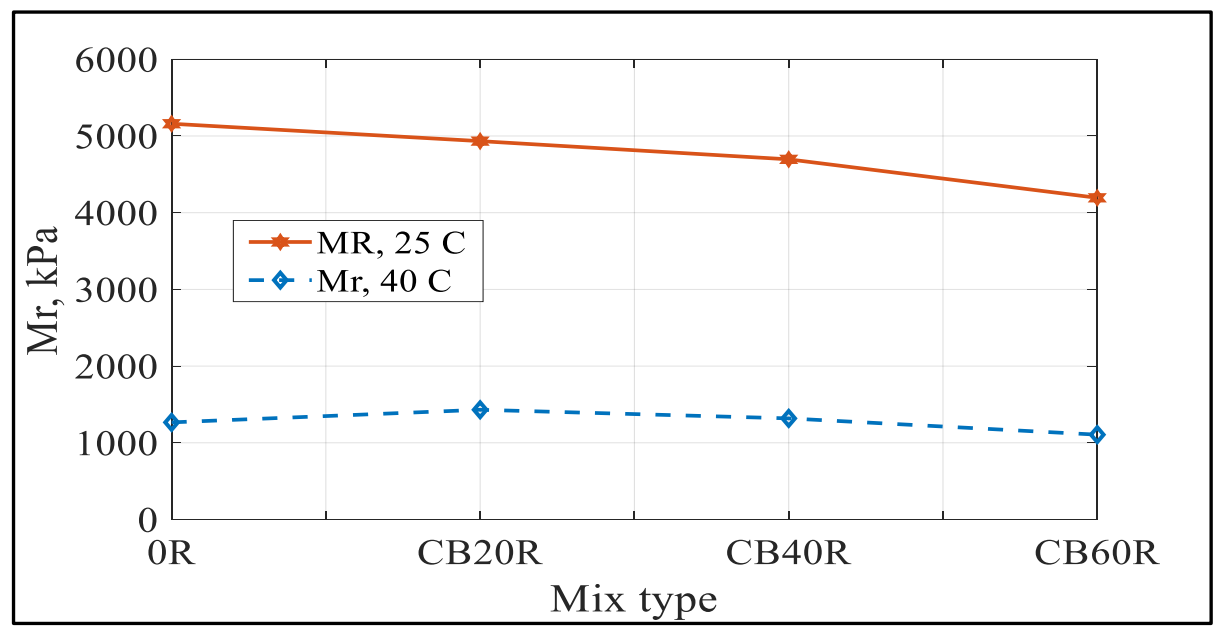

Figure 7, ITSM test results.fig

\section{Conclusion and recommendations for future works}

In this study, a new state of the art coating technique has been assessed through experimental investigation. The concept of the new double coating technique was developed based on combining of two main previous treatments after analyzing the performance of HMA/RCAs obtained by these treatments. According to the results of the conducted tests and analyses, the following conclusion can drown:

1. The RCAs is a lower quality material in terms of strength, density, and water absorption, therefore; different upgrading techniques have been suggested to remedy these defects before being used as HMA aggregates. Disappointedly, some treatments degrade some RCAs properties. In this study, coating the RCAs with CSP increases the water and bitumen absorption. Therefore, a second coating layer has been applied to seal up the pores presented into CSP coating layer to improve the durability of the DCRCAs.

2. The DCT reduces the water absorption of the DCRCAs and improves the strength of the interfacial bond between the double coated particles and bitumen as shown by the results of water absorption test and TSR test. This was a result of obstructing the pores presented 
onto the RCA-coated with CSP surfaces and improving the affinity between these particles and bitumen.

3. Because of the combined effect of the DCT, where the first coating layer upgrades the strength and the second coating layer upgrades the cohesion with bitumen, the stability values were either close or higher than those of HMA prepared with granite aggregates.

4. The results of TSD revealed that the DCT decreases the mobilized friction forces between the RCAs after the double coating action took place. In addition, the DCRCA-asphalt mixtures achieved TSW a lower than control mix. The TS obtained for mixtures designed with $20 \%, 40 \%$, and $60 \%$ of DCRCAs in the wet state was close to their TS in the dry state, therefore, TSR higher than $98 \%$ is obtained.

5. Although the HMA made with DCRCAs intended to serve as an intermediate layer, these mixtures are exhibited indirect tensile stiffness modulus fit the requirement for wearing and fatigue layers. In this regard, there is a reduction in the resilient modulus of HMA made with DCRCAs when tested at $25^{\circ} \mathrm{C}$. Preparation of the mixes with a lower quality aggregate, and the higher $\mathrm{OBC}$ of these mixes compared to the mix made with high-quality aggregates might produce such result. The DCRCA-asphalt mixes showed a noticeable stiffness improvement up to $40 \%$ granite aggregates substitution at elevated test temperature $\left(40^{\circ} \mathrm{C}\right)$. This improvement in the mix stiffness needs further investigation.

6. Whilst the results obtained by the current technique are encouraging, the biggest challenge for the DCT is its need for using materials which are non-sustainable and expensive. In this regard, one of the aims of the percent work is to open a new window in the research area of RCA-asphalt mixtures which might be followed by a series of improvements over time after more studies conducted in the field. 
ASTM. (2017). Standard Test Method for Indirect Tensile (IDT) Strength of Asphalt Mixtures (pp. 1-6). US: ASTM.

Australian/New Zealand Standard. (2013). Methods of sampling and testing asphalt Method 13.1: Determination of the resilient modulus of aspahlt-Indirect tensile method (pp. 1-13). Sydney: Standards Australia/Standards New Zealand.

Australian/New Zealand Standards. (2015). Compaction of asphalt by Marshall method and determination of stability and flow-Marshall procedure AS/NZS 2891.5-2015 (pp. 1-17). Sydney, NSW: Standards Australia/Standards New Zealand.

Austroads. (2007). Commentary to AG:PT/T232- Stripping potential of asphalt - Tensile strength ratio (pp. 1-10). Sydney: Austroads.

Austroads. (2008). Testing Asphalt in Accordance with the Austroads Mix Design Procedures (No. APT100/08). Retrieved from Sydney:

Bhusal, S., Li, X., \& Wen, H. (2011). Evaluation of Effects of Recycled Concrete Aggregate on Volumetrics of Hot-Mix Asphalt. Transportation Research Record: Journal of the Transportation Research Board, 2205(-1), 36-39. doi:10.3141/2205-05

Bhusal, S., \& Wen, H. (2013). Evaluating Recycled Concrete Aggregate as Hot Mix Asphalt Aggregate. 2(1), 252-265. doi:10.1520/ACEM20120053.

Chen, M. J., \& Wong, Y. D. (2013). Porous asphalt mixture with $100 \%$ recycled concrete aggregate. 14(4), 921-932.

Gómez-Meijide, B., \& Pérez, I. (2014). Effects of the use of construction and demolition waste aggregates in cold asphalt mixtures. Construction and Building Materials, 51, 267-277.

Gómez-Meijide, B., Pérez, I., Airey, G., \& Thom, N. (2015). Stiffness of cold asphalt mixtures with recycled aggregates from construction and demolition waste. Construction and Building Materials, 77, 168-178.

Gómez-Meijide, B., Pérez, I., \& Pasandín, A. (2016). Recycled construction and demolition waste in cold asphalt mixtures: evolutionary properties. Journal of Cleaner Production, 112, 588-598.

Grabiec, A. M., Klama, J., Zawal, D., \& Krupa, D. (2012). Modification of recycled concrete aggregate by calcium carbonate biodeposition. Construction and Building Materials, 34, 145-150.

Gul, W. A., \& Guler, M. (2014). Rutting susceptibility of asphalt concrete with recycled concrete aggregate using revised Marshall procedure. Construction and Building Materials, 55, 341349. doi:10.1016/j.conbuildmat.2014.01.043

Hou, Y., Ji, X., Su, X., Zhang, W., \& Liu, L. (2014). Laboratory investigations of activated recycled concrete aggregate for asphalt treated base. Construction and Building Materials, 65, 535542. doi:10.1016/j.conbuildmat.2014.04.115

Katz, A. (2004). Treatments for the improvement of recycled aggregate. Journal of Materials in Civil Engineering, 16(6), 597-603.

Lee, C.-H., Du, J.-C., \& Shen, D.-H. (2012). Evaluation of pre-coated recycled concrete aggregate for hot mix asphalt. Construction and Building Materials, 28(1), 66-71. doi:10.1016/j.conbuildmat.2011.08.025

Li, J., Xiao, H., \& Zhou, Y. (2009). Influence of coating recycled aggregate surface with pozzolanic powder on properties of recycled aggregate concrete. Construction and Building Materials, 23(3), 1287-1291. doi:10.1016/j.conbuildmat.2008.07.019

MRWA. (2017). Asphalt Wearing Course Specification 504. Perth, WA: Main Roads Western Australia.

Nassar, A. I., Mohammed, M. K., Thom, N., \& Parry, T. (2016). Mechanical, durability and microstructure properties of Cold Asphalt Emulsion Mixtures with different types of filler. Construction and Building Materials, 114, 352-363.

Paranavithana, S., \& Mohajerani, A. (2006). Effects of recycled concrete aggregates on properties of asphalt concrete. 48, 1-12. doi:10.1016/j.resconrec.2005.12.009 
Pasandín, a. R., \& Pérez, I. (2013). Laboratory evaluation of hot-mix asphalt containing construction and demolition waste. Construction and Building Materials, 43, 497-505. doi:10.1016/j.conbuildmat.2013.02.052

Pasandín, A. R., \& Pérez, I. (2014). Mechanical properties of hot-mix asphalt made with recycled concrete aggregates coated with bitumen emulsion. Construction and Building Materials, 55, 350-358. doi:10.1016/j.conbuildmat.2014.01.053

Pourtahmasb, M. S., \& Karim, M. R. (2014). Performance Evaluation of Stone Mastic Asphalt and Hot Mix. 2014.

Rafi, M. M., Qadir, A., Ali, S., \& Siddiqui, S. H. (2014). Performance of Hot Mix Asphalt Mixtures Made of Recycled Aggregates. Journal of Testing and Evaluation, 42(2), 20130004-20130004. doi:10.1520/JTE20130004

Saravanakumar, P., Abhiram, K., \& Manoj, B. (2016). Properties of treated recycled aggregates and its influence on concrete strength characteristics. Construction and Building Materials, 111, 611-617.

Standards Australia. (2005). Hot mix asphalt-A guide to good practice AS 2150-2005 (pp. 1-50). Sydney: Standards Australia.

Tam, V. W. Y. (2009). Comparing the implementation of concrete recycling in the Australian and Japanese construction industries. Journal of Cleaner Production, 17(7), 688-702. doi:10.1016/j.jclepro.2008.11.015

Wang, J., Vandevyvere, B., Vanhessche, S., Schoon, J., Boon, N., \& De Belie, N. (2017). Microbial carbonate precipitation for the improvement of quality of recycled aggregates. Journal of Cleaner Production, 156, 355-366.

Wong, Y. D., Sun, D. D., \& Lai, D. (2007). Value-added utilisation of recycled concrete in hot-mix asphalt. 27, 294-301. doi:10.1016/j.wasman.2006.02.001

Zhu, J., Wu, S., Zhong, J., \& Wang, D. (2012). Investigation of asphalt mixture containing demolition waste obtained from earthquake-damaged buildings. Construction and Building Materials, 29, 466-475. doi:10.1016/j.conbuildmat.2011.09.023

Zulkati, A., Wong, Y. D., \& Sun, D. D. (2013). Mechanistic Performance of Asphalt-Concrete Mixture Incorporating Coarse Recycled Concrete Aggregate. Journal of Materials in Civil Engineering, 25(9), 1299-1305. doi:10.1061/(ASCE)MT.1943-5533.0000668 